\title{
doispontos:
}

\section{Práticas de liberdade em Foucault}

\author{
Thiago Fortes Ribas \\ Pós-doutorando em Filosofia na PUC-SP \\ filosofiathiagoribas@gmail.com
}

\begin{abstract}
Resumo: Ao propor o diagnóstico do presente como tarefa de sua filosofia, Michel Foucault pensou a possibilidade de práticas da liberdade a partir de uma relação refletida de resistência aos campos de saber e de poder que formam nossa atualidade. Não se trata, desta forma, de pensar a liberdade como oposta aos regimes de saber e as relações de poder, mas antes de pensar a liberdade como uma prática possível no interior dos sistemas de verdade formados por estes campos. Pensando desta forma, Foucault se confronta tanto com os fundamentos do pensamento humanista, quanto com os princípios da análise do poder em termos jurídico-políticos. Assim, na investigação das formas de resistência frente a nosso presente, Foucault nos propõe uma filosofia como exercício arriscado de si mesmo e que seria inseparável de uma transformação dos outros.
\end{abstract}

Palavras-chave: Foucault; liberdade; discurso; poder; ética; cinismo.

\section{Pratices of freedom in Foucault}

Abstract: By assuming the diagnosis of the present as the task of his philosophy, Michel Foucault examined the possibilities of an exercise of freedom in terms of a reflective relation of resistance to the fields of knowledge and power that constitute our present time. This does not mean to think of freedom as opposed to regimes of knowledge and power relations, but rather to conceive of freedom as a possible exercise within the truth systems established by those power-knowledge relations. Accordingly, Foucault confronted the foundations of humanistic thought as well as the principles of an analytic of power defined under juridical-political terms. Thus, by analysing the ways in which one can resist against our present time, Foucault understood philosophy as a risky task concerning the possibility of self-transformation and the transformation of others.

Keywords: Foucault; freedom; discourse; power; ethics; cynicism.

Traçando um panorama sobre a questão da liberdade no pensamento de Michel Foucault, este artigo se divide em três momentos: primeiramente analisaremos esta problemática a partir das críticas dirigidas ao arqueólogo, na década de 1960, feita pela geração existencialista. Em um segundo momento trataremos da relação entre liberdade e poder tal como se estabelece, na década de 1970, em sua análise genealógica das relações de poder. Atento para a noção de vontade de verdade, Foucault denunciará o pensamento político-jurídico tradicional enquanto incapaz de perceber as relações de poder no interior dos discursos verdadeiros. Por fim, discutiremos como Foucault pensa o exercício da liberdade no final de sua produção teórica, mais especificamente em seu último curso no Collège de France, quando se coloca em consonância com certa militância filosófica característica do cinismo antigo por realizar sua filosofia como manifestação de uma verdade que põe em questão os valores constituídos. 


\section{LIBERDADE E DISCURSO NA ARQUEOLOGIA}

Desde da publicação de As palavras e as coisas (Les mots et les choses), em 1966, quando Foucault passou a ser uma referência mais significativa no cenário intelectual francês, ele foi acusado de negar a existência da liberdade humana com seus próprios princípios teóricos. No entanto, ao considerar as práticas discursivas e não-discursivas pelos sistemas inconscientes que determinam suas regras, para o próprio arqueólogo não se trataria de negar a liberdade, como afirmado por alguns de seus críticos (ERIBON, 1996, p. 104). Ao contrário, era preciso estudar os sistemas de pensamento por uma análise histórica comparativa de diferentes regularidades discursivas para, justamente, buscar a possibilidade do exercício da liberdade na recusa da naturalização dos saberes. Foucault afirma o seguinte nas últimas páginas de $A$ arqueologia do saber: "Eu não neguei, longe disso, a possibilidade de mudar o discurso: tirei dele o direito exclusivo e instantâneo à soberania do sujeito" (FOUCAULT, 1969, p. 272). O discurso precisa ser analisado em sua singularidade, sendo preciso renunciar aos pressupostos totalizantes que mascaram os acontecimentos discursivos. É preciso, segundo Foucault, descrever o funcionamento dos arquivos, dos conjuntos históricos de regras discursivas que formam objetos, sujeitos de enunciação, grades conceituais e estratégias teóricas, para então multiplicar as diferenças escondidas sob a ilusão que avalia todo discurso pelo recurso abstrato da razão humana.

Não avaliando os discursos, mas exercendo a análise de suas condições de possibilidade, a tarefa que a filosofia foucaultiana se propunha era a "[...] de expor este pensamento atrás do pensamento, este sistema atrás de todo sistema... Ele é o fundo sobre o qual nosso pensamento 'livre' emerge e cintila por um instante" (FOUCAULT, 1994a, p. 515). Dito de outra maneira, tratava-se de um trabalho que buscava expor os limites que o discurso impõe ao nosso modo de ser, de pensar e de agir nos livrando da ilusão de que nos desenvolvemos livremente na razão e na verdade. Somente então poderemos ter a experiência de estranhamento do que antes se apresentava como natural; somente então poderemos experimentar o perigo do que se apresentava como inocente. Desse modo a liberdade não poderia ser pensada como um transcendental, ou como uma marca característica do homem. A liberdade seria pensada nas pesquisas arqueológicas de Foucault como um exercício possível de se realizar quando se recusam os transcendentais que aprisionam nosso pensamento em um humanismo ingênuo, incapaz de enxergar as coerções que se camuflam sob supostas necessidades naturais. O Homem enquanto sujeito soberano de sua consciência e de sua liberdade não passaria de um correlato de Deus. Por isso, para o arqueólogo era preciso afirmar que existem estruturas inconscientes que nos governam sem que percebamos e que nos impedem de continuar com o pensamento narcísico da soberania do homem na História.

Com Simone de Beauvoir, Jean Paul Sartre formava na década de 1960 um enorme expoente de reflexão filosófico-política, e as críticas que ambos dirigiram contra As palavras e as coisas ecoaram entre seus admiradores. Foucault foi visto pela geração existencialista como um tecnocrata representante da burguesia e seu sucesso momentâneo nada mais seria do que poeira nos olhos da sociedade (D'ALLONNES, 2009, p. 170). A sociedade, aliás, seria aquilo que o arqueólogo ignoraria, assim como a história em seu movimento, pois confundiria o momento sincrônico de sua análise com a própria História. D’Allonnes reprova justamente essa suposta inaptidão de Foucault, que faria uma análise da estrutura e das palavras que se mostram na análise sincrônica do pensamento social, e negligenciaria o caráter diacrônico da linguagem que só poderia ser compreendido pela ação do homem enquanto sujeito da história (D’ALLONNES, 2009, p. 163).

A ênfase que Foucault dá às formações dos saberes em As palavras e as coisas torna o alvo da crítica ao seu trabalho mais previsível. Negar as bases da história dialética pelo estudo da estrutura do saberes faz com que seu pensamento apareça à geração anterior como se se tratasse da própria negação da política. 
À análise das estruturas do saber seria oposta a realidade dos conflitos da sociedade. Para o pensamento humanista, seria pela compreensão do desenvolvimento desses conflitos que se encontraria a chave da História, enquanto a exaltação do estudo das estruturas não seria mais que uma tentativa, vista como deliberada por alguns, de negá-la.

O contexto dos embates teóricos da década de 1960 não pode ser compreendido sem tomarmos em conta a querela entre os humanistas e os estruturalistas, sendo Foucault frequentemente associado aos segundos. Descombes $(1979$, p. 126) resume a crítica escandalizada da geração humanista contra as novas pesquisas estruturalistas da seguinte maneira: "As estruturas decidem e não o homem! O homem não é mais nada! Tal é a lição que a opinião reteve das pesquisas da antropologia estrutural: ao menos, se lêssemos os comentários escandalizados dos "humanistas" [...] O essencial, todavia, está em outro lugar." Para esta "opinião" que Descombes descreve, formada sob os pressupostos humanistas, a análise estrutural, entrando em voga neste período do início da década de 1960, negaria a autonomia do homem, pois o transformaria em algo completamente governado por estruturas externas. Por certo, o debate geral se empobrecia quando dividido entre duas opções: o homem e sua liberdade ou as estruturas. Os ganhos políticos das diferentes formas de realizar as análises discursivas não poderiam ser compreendidos por meio desses termos.

Descombes argumenta que não deveria ser menosprezada a problematização política do laço simbólico das instituições, isto é, a questão da operação de um sistema de signos sobre uma comunidade. Afinal, trata-se de pôr em jogo os poderes ocultos que uma linguagem mantém. Ao iniciar a semiologia, Saussure já havia fornecido as primeiras bases para as diferentes análises discursivas que ganhariam corpo com o estruturalismo1: "Podemos, portanto, conceber uma ciência que estuda a vida dos signos no seio da vida social; ela formaria uma parte da psicologia social, e por consequência da psicologia geral; nós a nomearemos semiologia". (SAUSSURE, 2005, p. 33). Aquilo que diria respeito a uma liberdade do homem, ou as vontades humanas, precisaria ser deixado de lado para realizar um estudo que retenha os traços da língua, uma vez que "[...] o signo escapa sempre, em certa medida, à vontade individual ou social, esta é sua característica essencial; mas é isto que menos aparece à primeira vista" (SAUSSURE, 2005, p. 34). A tarefa estruturalista de desconstrução de uma linguagem dominante se opunha ao projeto de uma "política progressista" transcendental. Com suas narrativas da história como projeto de emancipação do homem pelo próprio homem, tal política progressista possuía um objetivo claro e, por isso, tinha em eventos tais como a revolução francesa a comprovação do progresso a caminho da tomada de consciência. As pesquisas estruturalistas, por sua vez, não partiam de um projeto definido a se realizar, realizavam, ao contrário, entre outras coisas, a denúncia da mitologia da ideologia política humanista.

Contra a forma de "engajamento" defendido pelos humanistas que, por ignorar os avanços teóricos de seus contemporâneos, intensificariam a simbologia mitológica de um discurso ultrapassado, perdendo a possibilidade de transformar as condições de pensamento, Foucault alertava para a importância das análises estruturais na ação política:

Creio que uma análise teórica e exata da maneira como funcionam as estruturas econômicas, políticas e ideológicas é uma das condições absolutamente necessárias para própria ação política, visto que a ação política é uma maneira de manipular e eventualmente mudar, inverter e transformar as estruturas. Em outros termos, a estrutura se revela na ação política ao mesmo tempo que a ação política trabalha e modifica as estruturas. (FOUCAULT, 1994a, p. 655).

Se para Mallarmé e seus herdeiros tocar nas formas significantes seria subverter a comunidade, para os humanistas a pesquisa que privilegia a linguagem em seu momento inativo não poderia esquecer suas limitações. Para os humanistas, portanto, as análises das estruturas linguísticas deveriam fornecer, segundo uma filosofia da consciência, as ferramentas para reintegrar o irracional, que delimita um sistema significante 
da linguagem, a uma razão ampliada, de modo que seja possível explicar o inconsciente. Ater-se ao estático na linguagem seria negar sua dimensão de originalidade, ou seja, seria ignorar o momento de criação do novo que só poderia ser explicado pela ação da consciência humana.

Para o pensamento humanista da geração sartriana, os detentores de um novo ímpeto linguista acreditariam que o pensamento e a linguagem são o mesmo, "[...] como se a própria linguagem não fosse falada" (SARTRE, 2009, p. 79). Sartre afirma que, em um primeiro nível da linguagem, ela pode ser apresentada como um sistema refletor de uma unificação social no qual é possível uma análise linguística do tipo estruturalista. Tal análise se justificaria visto que a linguagem apareceria neste nível como coisa sem o homem. Entretanto, essa coisa inerte que aparece sem o homem foi, e sempre será, aberta pelo homem. Assim, Sartre compreende que na análise estruturalista da linguagem se deva admitir a existência de um sistema de relações no qual o sentido de cada elemento se faz em relação ao todo do sistema, mas, para que isso aconteça, deve-se admitir também que a linguagem só existe quando falada pelo homem. Deste modo, faz-se necessário considerar um segundo nível da linguagem no qual não estão em questão estruturas já inteiramente constituídas "[...] que existiriam sem nós. [... ] A estrutura só se impõe a nós na medida em que ela é feita por outros" (SARTRE, 2009, p. 78-79). Para o existencialista, é somente considerando a História pelo processo totalizador da praxis que se poderá compreender o nível em que linguagem se mostra original.

Ao contrário, para os partidários da análise discursiva de herança saussuriana, a criação do sentido se dá “[...] a partir da natureza relacional da linguagem, independente de toda atividade criadora de uma consciência ou do agir humano" (PALTRINIERI, 2012, p. 77). A recusa que Foucault e os representantes do estruturalismo fazem das filosofias do sujeito está assentada na hipótese de que "[...] o pensamento não tem necessidade do ato doador de sentido de um cogito para existir, porque a origem do sentido está na própria linguagem" (PALTRINIERI, 2012, p. 78). Com a discordância sobre a origem do sentido encontrar-se na consciência ou na própria linguagem, invertem-se os valores quando olhamos através da perspectiva existencialista ou das perspectivas do estruturalismo e de Foucault. Do lado sartriano, a onda estruturalista da qual, segundo essa perspectiva, a arqueologia foucaultiana faria parte, não passa de um entusiasmo equivocado pelo estudo do momento sincrônico da história que faz com que se esqueçam as limitações de tal análise. Do ponto de vista foucaultiano, os humanismos defensores da história dialética totalizante e da primazia da atividade constituidora de sentido na consciência estariam presos a um pensamento em vias de desaparecer porque tem seu fundamento no Homem como sujeito e objeto de conhecimento, sendo este entendido como uma figura histórica frágil e recente da configuração do saber moderno.

Somando-se as diferenças do ponto de partida teórico, vemos que para o existencialismo os estudos marginais realizados pelos chamados "estruturalistas" apareciam como pouco úteis e politicamente vazios. Como tais estudos, não fornecendo um alvo concreto às práticas, ocupando-se com as organizações internas das estruturas linguísticas, não acabariam favorecendo a manutenção dos poderes dominantes da burguesia? Pois bem, responderia o arqueólogo, é somente através de estudos como esses que podemos traçar um "diagnóstico do presente" (FOUCAULT, 1994a, p. 606), caracterizado por Foucault, já na década de 1960, como a tarefa da filosofia contemporânea depois de Nietzsche. Antes de se colocar em luta por um ideal humanista definido, como se ele fosse válido universalmente, para Foucault é preciso se perguntar: "quem nós somos hoje? O que é esse "hoje" no qual nós vivemos?" (FOUCAULT, 1994a, p. 613). Em tal problematização temos que atentar para historicização desse "nós". Não se trata de um questionamento sobre o nosso ser enquanto sujeitos transcendentais, mas sim enquanto singularidades históricas.

Desse modo, o diagnóstico arqueológico não se assemelha com as verdades postuladas por uma filosofia prescritiva. Ele surge como tarefa filosófica justamente porque é renunciado o projeto de uma moral universal. Como afirma Foucault em As palavras e as coisas: "O pensamento moderno nunca pode, de fato, propor uma 
moral: mas a razão disso não é que ele seja pura especulação; justamente o contrário, ele é desde o começo, e na sua própria espessura, certo modo de ação" (FOUCAULT, 1966, p. 339). Não há possibilidade de se pensar uma moral universal quando o pensamento não é mais compreendido como transcendental. O pensamento é desde o momento de sua emergência uma ação, uma imposição de uma perspectiva, e como tal sempre exerce sua força nas relações de poder. A moral com pretensões universais só é possível quando se postula verdades transcendentais. Em Kant, por exemplo, como afirma Foucault, "[...] a possibilidade de uma crítica e sua necessidade estavam ligadas, através de certos conteúdos científicos, ao fato de que existe conhecimento" (FOUCAULT, 1963, p. XII). O estatuto que a crítica kantiana se atribui tem a pretensão de alcançar uma validade atemporal e universal porque supõe um conhecimento transcendental. Ao contrário, o pressuposto do arqueólogo não é a existência de qualquer conhecimento, e sim a existência da linguagem. Dessa forma a sua crítica justifica-se diferentemente no fato de que "[...] estamos historicamente consagrados à história, à paciente construção de discursos sobre os discursos, à tarefa de ouvir o que já foi dito" (FOUCAULT, 1963, p. XII). O diagnóstico, assim entendido, é o resultado da filosofia que se faz a marteladas, daquela que interpretando os discursos oferece uma avaliação: "[...] o arqueólogo, como o filósofo nietzscheano, é levado a operar com golpes de martelo" (FOUCAULT, 1994a, p. 599). O martelo não deve ser entendido como instrumento para fixar ou para simplesmente destruir algo, mas antes para testar, fazer ressoar para que seja possível avaliar o som. Também poderíamos pensar na imagem do médico que testa os reflexos de seu paciente com leves golpes em regiões precisas. O diagnóstico deve levar em conta a especificidade daquilo que está sendo analisado. Ele serve para um momento determinado, e não para sempre: "O diagnóstico assim entendido não estabelece a autenticação de nossa identidade pelo jogo das distinções. Ele estabelece que somos diferença, que nossa razão é a diferença dos discursos, nossa história a diferença dos tempos, nosso eu a diferença das máscaras". (FOUCAULT, 1969, p. 172-173). Trata-se de buscar a singularidade e a alteração possível, não se trata de buscar aquilo que há de permanente. Para compreender o que nos delimita na atualidade, nos impedindo de experimentar modos diferentes de ser, não devemos nos interrogar sobre uma essência secreta, mas sim sobre aquilo está mais manifesto em nossas práticas e que, no entanto, pode ser transformado.

Colocando-se a tarefa do diagnóstico do presente, para Foucault o seu procedimento filosófico precisa se reconhecer sempre estratégico e experimental. Trata-se de um trabalho sobre os discursos que é simultaneamente histórico, filosófico e político, tendo efeitos de transformação no campo discursivo em que atua e no próprio pensamento daquele que o executa. Não se trata de demonstrar algo preexistente, ou algo escondido que passou desapercebido pelos outros, mas sim de produzir um saber sobre e também contra os saberes constituídos:

\footnotetext{
Mas o diagnóstico, ele é obra do historiador, do filósofo, daquele que faz a política? Eu não sei. De qualquer modo, trata-se de uma atividade de linguagem que é para mim muito profunda. No fundo não escrevo [ ... ] para demonstrar aquilo que, para mim e por mim mesmo, eu já havia demonstrado e analisado. A escrita consiste essencialmente em empreender uma tarefa graças a qual e no final da qual poderei, por mim mesmo, encontrar qualquer coisa que não havia visto no começo. Quando começo a escrever um estudo, um livro, não importa o que, não sei realmente onde isso vai chegar, nem ao que isso irá servir, nem o que demonstrarei. (FOUCAULT, 2011b, p. 41).
}

O diagnóstico como tarefa da filosofia é simultaneamente um trabalho de reconstrução do passado e de retrato do presente: é na comparação com os discursos que não são mais os nossos que se encontra a possibilidade situarmos nosso pensamento atual. É descrevendo a modernidade como idade das antropologias, compreendida como a forma discursiva principal da Europa entre 1790-1810 até 1950, e através de uma comparação com o Classicismo e o Renascimento, que justamente nos desprenderemos dela. O diagnóstico é uma atividade teórica indissociável de uma prática, uma vez que traçando as condições de possibilidade do nosso discurso provoca a sua transformação imediata. As fronteiras tradicionais entre filosofia, história e política não se aplicam e não importam àquele que diagnostica. 


\section{LIBERDADE E PODER NA GENEALOGIA}

Em sua primeira aula no Collège de France intitulada A ordem do discurso, Foucault nos chama a atenção para uma inquietação geral das sociedades em relação ao discurso, “[...] uma profunda logofobia, um tipo de medo surdo contra estes acontecimentos, contra esta massa de coisas ditas, contra o surgimento de todos estes enunciados, contra tudo que pode haver aí de violento, de descontínuo". (FOUCAULT, 1971, p. 52). Especificamente em nossa sociedade, tal inquietação é conjurada por diferentes procedimentos, externos e internos ao próprio campo discursivo. Se não tomarmos o discurso como pura expressão do real, ou através de qualquer um dos temas que procuram negar a sua existência material, vemos que há em sua ação “[...] poderes e perigos que mal se imaginam” (FOUCAULT, 1971, p. 10). Vemos, então, que tomar a palavra é um ato perigoso, pois a partir do momento em que algo é enunciado, e, portanto, materializado, por mais que esteja destinado a uma duração finita, aquele que o enunciou não pode controlar seus efeitos nem o tempo de sua existência. Percebe-se, então, como afirma Gros, que a problemática de Foucault nesse momento permanece sendo a "[...] do discurso como campo de existência anônima no qual o sujeito filosófico não reencontra seus frutos” (GROS, 2012, p. 55). Ou seja, as aquisições teóricas provenientes da noção de prática discursiva, que negavam a posição filosófica do sujeito como origem de sentido, desenvolvida em A arqueologia do saber, servem aqui de base para seu pensamento. É a partir desta base teórica, e não contra ela ou em ruptura com ela, que Foucault parte para a interrogação sobre os procedimentos históricos de delimitação do discurso que buscam ordenar os seus poderes.

Seu ensino no Collège de France recebe o título de "História dos sistemas de pensamento", e, como afirma Foucault no resumo do seu primeiro curso, ele estará ancorado em pesquisas anteriores que "[...] haviam permitido reconhecer um nível singular entre todos os que possibilitam a análise dos sistemas de pensamento: aquele das práticas discursivas” (FOUCAULT, 2011c, p. 217). Reconhecendo neste nível uma sistematicidade que não é lógica nem linguística, Foucault aponta para sua concretização em “[...] conjuntos técnicos, em instituições, em esquemas de comportamento, em tipos de transmissão e de difusão, em formas pedagógicas que simultaneamente as impõem e as mantêm” (FOUCAULT, 2011c, p. 217). Aqui, tanto quanto já era afirmado em Arqueologia do saber, as práticas discursivas encontram-se em uma correlação múltipla com as práticas não-discursivas. A novidade, entretanto, aparece naquilo que neste curso Foucault opõe ao sujeito de conhecimento. Por um lado, contra a pressuposição de um sujeito de conhecimento capaz de explicar os princípios do discurso, no livro de 1969 Foucault havia oposto os sistemas múltiplos de pensamento, os quais poderiam ser analisados em suas regularidades, possibilitando deste modo a descrição do nascimento e da morte da própria forma de pensamento antropológico que requisitava o homem como tal sujeito. Por outro lado, no curso de 1970-1971, iniciando os estudos genealógicos, Foucault afirma que os princípios de exclusão e de escolha que atravessam as práticas discursivas “[...] designam uma vontade de saber, anônima e polimorfa, sujeita a transformações regulares e considerada num jogo de dependência identificável” (FOUCAULT, 2011c, p. 278). Assim, neste curso inicial, que tem como tema a noção de vontade de saber, Foucault contrapõe principalmente as concepções aristotélicas e nietzscheanas sobre esta noção, com o objetivo de elaborar um modelo de análise das relações entre conhecimento e desejo, saber e poder, verdade e interesse, o qual é muito diverso daquele da tradição filosófica platônica e aristotélica.

No estabelecimento de seus discursos filosóficos, tanto Aristóteles quanto Platão desenvolvem uma mesma "exigência teórica" contra a sofística. Ambos precisam "[...] fazer com que a vontade de conhecer se fundamente única e exclusivamente no que é preliminar ao próprio conhecimento; [precisam] fazer com que o desejo de conhecer esteja inteiramente englobado no interior do conhecimento" (FOUCAULT, 2011b, p. 17). Para Foucault, trata-se de mostrar que Platão e Aristóteles precisavam negar um desejo exterior ao conhecimento que o animasse, ou seja, negar uma vontade de verdade que fosse capaz 
de implicar a instituição do conhecimento com desejos parciais. $\mathrm{O}$ discurso que ligaria desejos externos ao conhecimento era o discurso sofístico, aquele que compreenderia o saber como um bem a ser vendido, sendo por isso mesmo um falso conhecimento, um não-conhecimento, que Aristóteles haveria separado completamente do discurso filosófico.

De um lado, Platão utilizava-se da reminiscência para interiorizar o desejo de conhecer no próprio conhecimento, afirmando que "[...] antes mesmo de desejares saber, sabias, já havias sabido" (FOUCAULT, 2011b, p. 17). $\mathrm{Na}$ reminiscência, se somos levados ao conhecimento é por já o possuirmos, de modo que somos levados simplesmente a lembrar o que já sabemos. No Fédon, com o intuito de provar a imortalidade da alma, Sócrates argumenta o seguinte: "[...] o nosso conhecimento é somente recordação. Se este princípio é exato, temos de ter aprendido em outro tempo as coisas de que nos recordamos. E isso não é possível se nossa alma não existir antes de receber esta forma humana”. (PLATÃO, 2004, p. 135). Desse modo o conhecimento não seria aparentado ou comprometido com qualquer imposição perspectiva do nosso corpo, nem tampouco seria uma aquisição que forneceria vantagens ao seu enunciador, antes, o conhecimento seria livre de qualquer arbitrariedade enquanto considerado como a lembrança operada pela atividade da alma das ideias universais e necessárias.

Por outro lado, negando o tema da reminiscência platônica, no início do seu livro que posteriormente será organizado e intitulado por estudiosos de seu pensamento como Metafísica, Aristóteles defende um desejo natural ao conhecimento em todo homem: "Todos os homens têm, por natureza, desejo de conhecer: uma prova disso é o prazer das sensações, pois, fora até da sua utilidade, elas nos agradam por si mesmas" (ARISTÓTELES, 1984, p. 11). Aqui, Foucault chama a atenção para a prova aristotélica desta naturalidade do desejo de conhecer no homem. Para o estagirita temos algo como uma sensação, que é especificado como uma satisfação ao conhecer, que se dá apesar da inutilidade do conhecimento. Ora, para Aristóteles, se as sensações de prazer são explicadas pela utilidade que as ações têm para aqueles que as executam, como no caso do prazer que temos ao nos alimentar, que é explicado pela demanda de nutrição dos nossos organismos, ao contrário, tal satisfação ao conhecer, face à inutilidade do conhecimento, que não supre nenhuma necessidade corporal, só pode ser explicada porque o conhecimento estaria ligado à nossa causa final, visto que somos portadores de uma alma racional.

A satisfação que encontramos no conhecimento, para Aristóteles, é aquela da felicidade da contemplação, e não se confunde com qualquer prazer corporal, visto que este último não diferencia o nosso ser dos outros animais. Seguindo tal raciocínio aristotélico sobre a natureza do conhecimento, Foucault nota que, "[...] imediatamente o corpo, o desejo são elididos" (FOUCAULT, 2011b, p. 14). Requisitada como causa final do homem, a contemplação filosófica existe por si mesma enquanto ciência "[...] teorética dos primeiros princípios e das causas” (ARISTÓTELES, 1984, p. 14), sendo livre de qualquer propósito externo. Considerada sob tais premissas a filosofia ganha um estatuto elevado e distingue-se de toda baixeza das sensações corpóreas que caracteriza o desejo animado pela utilidade. Na concepção de Aristóteles, o desejo que anima a contemplação filosófica não é da mesma natureza e nem se aparenta aos prazeres mundanos próprios a todo animal, mas revela-se ligado à singularidade humana, ou seja, à sua causa formal, definida pela sua alma racional.

Se, por um lado, para Aristóteles a filosofia seria coagida pela verdade e alcançaria seu "efeito de verdade" através de silogismos, a formação do sofisma, ao contrário, seria movida pelo interesse pecuniário e se aproveitaria da materialidade dos símbolos linguísticos para enganar, sendo o próprio sofisma nada mais que "uma tática interna a essa materialidade" (FOUCAULT, 2011c, p. 46). Para o pensamento aristotélico, o sofisma está fora do universo de sentido em que se podem distinguir os enunciados verdadeiros dos 
enunciados falsos, porque nele “[...] é sempre a materialidade do discurso que está posta em jogo em seus diferentes aspectos" (FOUCAULT, 2011c, p. 44). Opera-se, nesta recusa do discurso sofístico, motivada pela razão de que ele seria identificado como aquele que se dá na materialidade dos signos, a construção de uma realidade ideal dos conceitos na qual a filosofia poderá conceder a si mesma a possibilidade de ser comandada pela "necessidade conceitual" (FOUCAULT, 2011c, p. 48). A sofística se desenvolveria na materialidade do discurso, ao passo que a filosofia se desenvolveria no campo conceitual do lógos. A filosofia estaria livre, portanto, da sombra da materialidade discursiva. Assim, conclui Foucault, o sofisma só pôde ser totalmente excluído da filosofia quando Aristóteles “[...] tem a ousadia de fazer da coisa dita, em sua materialidade, uma sombra irreal que ronda a realidade ideal do $\lambda$ ó $o s$ [lógos]” (FOUCAULT, 2011c, p. 50).

Para Foucault o pensamento filosófico que permaneceu na tradição aristotélica é aquele que mantém a primazia da identidade conceitual sobre a diferença. Tal pensamento, ao fazer da diferença simplesmente algo em relação à identidade, não consegue pensar a diferença por ela mesma. Pressupõe, assim, a naturalidade do campo conceitual, sem perceber como o seu acontecimento histórico impôs "a analogia de uma semelhança” (FOUCAULT, 2011c, p. 203) às múltiplas diferenças. Contra o pensamento conceitual da filosofia como algo natural, Nietzsche (2001, p. 139) já afirmava que "[...] a tendência predominante de tratar o que é semelhante como igual - uma tendência ilógica, pois nada é realmente igual - foi o que criou todo fundamento para a lógica”. Assim, na trilha de Nietzsche, para Foucault a diferença deve ser pensada como primordial, sendo as identidades conceituais sempre uma imposição secundária. Na perspectiva nietzscheana que a filosofia foucaultiana busca explorar, o momento platônico e aristotélico é aquele em que a filosofia produz um espaço para que o conhecimento seja possível ao interiorizar a diferença, recusando-se a pensá-la como constituinte.

A arqueologia já denunciava como, através da pressuposição do homem como sujeito de conhecimento, o pensamento filosófico da modernidade negava-se a perceber a materialidade de seu próprio discurso. Na letra do arqueólogo, tal materialidade ditava as suas condições de possibilidade. Desta forma, qualquer discurso estaria sujeito às condições que o antecedem e possibilitam. As filosofias do sujeito recusavam-se, por sua vez, a reconhecer a incontornável finitude e contingência de todo discurso, concedendo ao próprio discurso a possibilidade de prescrever leis universais. Assim, a liberdade em relação ao desejo que tais filosofias concedem a si mesmas é preservada na "antinomia entre saber e poder" (FOUCAULT, 1994b, p. 570), sustentada também por outros discursos atuais com estatuto de verdadeiros. Agora, no início da genealogia Foucault mostra que tal atitude negadora da materialidade como parte incontornável de todo discurso é herdeira de uma antiga vontade de verdade, colocando em jogo de maneira explícita uma relação de poder que atravessa todo discurso.

Como afirma Colombani (2008, p. 102), para Foucault o pensamento metafísico da verdade pura não é "[...] meramente um ramo da filosofia; se trata bem mais de um modelo de instalação, de um modo de conceber o real, que irradia suas ferramentas interpretativas e constrói um universo de instalação e sujeição". Assim, ainda hoje o discurso filosófico e o discurso científico pretenderiam alcançar a neutralidade de uma necessidade transcendental porque seriam incapazes de admitir que qualquer campo discursivo é uma construção histórica interessada em estabelecer verdades.

Ao perguntarmos sobre a verdade quando nos colocamos "no interior de um discurso" (FOUCAULT, 1971, p. 16) (de um campo proposicional filosófico ou cientifico), ou seja, no interior de um campo de sentido já estabelecido, e aceitando de partida toda rede conceitual que este campo impõe, não perceberíamos os efeitos de poder que são atribuídos ao discurso verdadeiro. Nesta ordem significante, aquilo que a verdade do discurso obriga seria considerado uma necessidade oposta a qualquer arbitrariedade, mobilidade, 
institucionalidade e violência, pois tais características são "[...] impensáveis numa escala de verdade proposicional” (CANDIOTTO, 2010, p. 52). Por sua vez, a verdade que historicamente aprendemos a desejar precisa perpetuar tal ilusão. Para genealogia foucaultiana, por causa de um desejo de verdade, engrandecido e internalizado em nós pela sua duração milenar, não percebemos a construção histórica de um campo discursivo em que verdades e falsidades são possíveis. Para preservar a suposição de naturalidade do nosso pensamento não percebemos nem a existência do campo discursivo em que nos encontramos nem o desejo que o mascara.

Manter o discurso no registro da designação, como se, de uma forma ou de outra, ele simplesmente nomeasse o mundo, como se fosse possível uma relação inocente entre as coisas e as palavras, seria perpetuar a ilusão de uma distinção possível entre o discurso filosófico coagido pela necessidade da verdade e o discurso desonesto dos sofistas. Separar um discurso preso unicamente à inocente necessidade conceitual, que buscaria a adequação a um conteúdo sensível, de um discurso político, que estaria comprometido porque seria perpassado pelas relações de poder, é deixar de reconhecer a vontade de verdade que institui qualquer campo conceitual. Assim, é preciso reconhecer, previamente ao registro interno de qualquer discurso, uma dispersão originária na qual um acontecimento discursivo tem lugar, na qual ele "[...] se dispersa entre instituições, leis, vitórias e derrotas políticas, reivindicações, comportamentos, revoltas, reações" (FOUCAULT, 2011c, p. 187). Ou seja, para "subverter a ordem do significante", tornando o discurso em si mesmo um campo de batalha política, precisamos contornar o "sistema de purificação" (FOUCAULT, 2011c, p. 190) histórico que, ao inventar um espaço próprio ao discurso de verdade, mascara sua materialidade e seu caráter de acontecimento.

Problematizar através de Nietzsche a concepção tradicional (platônica e aristotélica) da verdade, negando-lhe os caráteres de neutralidade, de fidedignidade, de unidade e de originalidade, permite a Foucault pensar uma noção de poder que também será diversa da forma como ela tradicionalmente era pensada na filosofia política. Se, desde a Idade Média, certo pensamento jurídico-político nos acostumou a pensar a noção de poder em termos de legitimidade ${ }^{2}$, perguntando-se pela sua verdadeira forma, agora, com Foucault vemos que tal questionamento encontra-se interiorizado em uma forma de pensamento mascarada por nossa milenar vontade de verdade. Ou seja, o pensamento político que se formula no interior do direito encontra-se em uma forma de pensar que preserva os operadores filosóficos de libertação do discurso em relação aos interesses exteriores ao próprio ato de conhecimento. Nos termos da tradição filosófica jurídico-política, o poder somente poderá ser considerado justo ou autoritário, legítimo ou não, verdadeiro ou falso. A própria questão sobre a legitimidade ou ilegitimidade dos exercícios do poder aparece como incontornável à filosofia política pelo legado da investigação sobre a verdade universal. No entanto, considerando a verdade como efeito de uma vontade de saber, tal questionamento sobre a legitimidade aparece como resultado de processos históricos que o precederam, de forma que uma tarefa filosófica distinta se anuncia para pensarmos a política: descrever as relações de poder que atravessam os discursos de verdade.

Estando preso à concepção metafísica de verdade, o pensamento político filosófico apresentou-se frequentemente ligado a uma avaliação do poder em termos jurídicos, posicionando-se fora da história, sob um olhar transcendente. Para Foucault, enquanto interrogarmos o poder acerca de sua legitimidade ou ilegitimidade, sobre o bem ou o mal que ele exerce, ainda estaremos presos a um pensamento incapaz de interrogar as relações de poder como acontecimentos históricos. Ainda presa à vontade de verdade, a teoria política continuou um "[...] sistema de representação do poder que foi em seguida transmitido às teorias do direito: a teoria política permaneceu obcecada pelo personagem do soberano" (FOUCAULT, 1994c, p. 150). Perguntar-se pela legitimidade, pelo direito, pela legalidade quando nos voltamos para a 
análise do poder seria adotar uma busca por fundamento longínquo que deveria pautar nossas ações na objetividade de uma verdade em que todos poderiam se reconhecer.

Assumindo-se inserida em relações de poder a filosofia não terá um papel jurídico-legislador, não falará de um lugar privilegiado trazendo a norma para todos os outros lugares, mas, ao contrário, reconhecendo as condições históricas de possibilidade de seu próprio saber, fará com que este saber atue na elucidação e intensificação das relações de poder que se escondiam da nossa percepção sob o véu da legitimidade. Como afirma Foucault, o saber histórico produzido nas análises genealógicas "[...] não é feito para compreender, ele é feito para cortar" (FOUCAULT, 1994b, p. 148). O valor político de sua abordagem está em tornar visível a multiplicidade de forças concorrentes que são abafadas em nome de um suposto apaziguamento, sua força está em mostrar que aquilo que se vê como pacificação em uma perspectiva, mesmo que esta perspectiva seja hegemônica, esconde sempre um jogo de dominações violentas. Não se trata de compreender a realidade, como se o seu discurso pudesse conter a verdade. O saber genealógico corta o que estava cristalizado pela naturalização das práticas, fragmenta, assim, aquilo que se impunha como universal e constituía os limites de nosso modo de ser.

Deste modo, o papel de sua filosofia não será o de “[...] descobrir o que estava escondido, mas o de tornar visível aquilo que precisamente é visível, ou seja, de fazer aparecer aquilo que de tão próximo, aquilo que de tão imediato, aquilo que de tão intimamente ligado a nós mesmos, não o percebemos. (FOUCAULT, 1994c, p. 540-541)". Sua analítica do poder posiciona-se, então, no interior de lutas específicas descrevendo fatos que eram ativamente esquecidos em prol da narrativa dominante e que produziam, por exemplo, uma forma de vida como normal, ou seja, os fatos cujos esquecimentos contribuíam ao funcionamento de um assujeitamento por uma dominação mascarada. Para Foucault, trata-se de mostrar que "[...] ao pensarmos as relações de poder segundo o modelo das relações jurídicas, mascara-se o fato da dominação" (DUARTE, 2010, p. 215-216). Se o campo do saber que estrutura os limites das nossas prática está constantemente em disputa, qualquer tentativa de exaurir a possibilidade da crítica transformadora deste campo pela imposição de uma verdade de valor universal se identificará sempre com uma opressão que busca esconder-se para garantir seu funcionamento.

Se a filosofia política ainda condicionada por uma noção de verdade como descoberta buscava as regras ideais para o jogo político, isso se dava porque ela era incapaz de reconhecer que quaisquer normas que se coloquem como universais estarão sempre negando seu incontornável posicionamento histórico e político para silenciar posições concorrentes. Assim, em vez de funcionar como crítica das relações de poder, a filosofia que se coloca em posição de julgar a legitimidade do poder assume continuamente a posição que mascara a pluralidade de forças. Neste sentido, Lorenzini nos mostra porque, segundo a visão foucaultiana, a análise do poder em termos jurídicos seria incapaz de efetivar uma verdadeira crítica às relações de poder, pois “[...] a força crítica de uma filosofia política que, tendo por objetivo colocar em questão as instâncias de poder, acaba, no entanto, retirando seus conceitos fundamentais dos discursos fabricados por elas, sem os submeter à problematização, é neutralizada desde o início. (LORENZINI, 2014, p. 11-12)”. Em resumo, interrogar o poder por uma abordagem jurídica é, desde o início, adotar, ao mesmo tempo, uma lente inadequada às vicissitudes das relações de poder, porque voltada ao encobrimento da multiplicidade; do mesmo modo, é também adotar uma posição política ligada às formas hegemônicas de poder estabelecidas em nossa sociedade, porque tal concepção as reforça ao valer-se de seu campo epistemológico.

Deste modo, com o tema do diagnóstico da atualidade por um trabalho de análises localizadas sobre as estruturas de saber e as estratégias de poder que nos perpassam, trata-se, para Foucault, não de encontrar a verdade fundamental de nós mesmos, mas sim de encontrar formas de deixar de ser o que somos. 
Trata-se de uma pesquisa que "[...] busca relançar o mais longe e o mais amplamente possível o trabalho indefinido da liberdade" (FOUCAULT, 1994d, p. 574). O trabalho genealógico empenha-se por uma alteração constante do nosso ser que não deveria pretender um destino fixo, puro ou transcendente, uma vez que não há uma verdade humana a perseguir e muito menos um regime de poder fundado em qualquer legitimidade. Assim, buscar a alteração daquilo que nos é imposto como o nosso ser em um momento histórico seria investir em uma certa prática de liberdade na recusa de se deixar capturar por sistemas históricos de verdade. Longe de qualquer noção transcendente, a liberdade aparecerá, então, como uma resistência face aos poderes que nos constituem, como uma prática possível que se efetua sempre referindo-se a determinada coerção. Na conferência de 1978, publicada posteriormente sob o título O que é a crítica?, Foucault chamará esta prática de liberdade de "atitude crítica" (FOUCAULT, 2015, p. 36), como um meio de evitar ser governado de um modo particular e em nome de certos princípios. Tal insubordinação em pontos específicos, mas fundamentais na constituição do nosso cotidiano, é a marca da sua ação política na desestabilização dos saberes hegemônicos.

\section{A CORAGEM DA VERDADE E A ÉTICA COMO LIBERDADE REFLETIDA}

Em seus últimos estudos, Foucault refletiu sobre sua própria ação intelectual ao investigar a relação entre verdade e subjetividade no cinismo. Essencial à compreensão dos próprios gestos filosóficos foucaultianos, vemos aparecer a partir do curso de 1982, intitulado A hermenêutica do sujeito, algo como uma genealogia do engajamento pessoal em que uma forma de vida se construiria pela reflexão incessante sobre os valores, bem como por certa coragem exigida para a prática da verdade. Na visão de Foucault (1994d, p. 691) as suas pesquisas estariam ligadas implicitamente a esta exigência de coragem: "[...] todo meu trabalho consiste em mostrar que a história é atravessada por relações estratégicas que são, por consequência, móveis e que podemos mudá-las. Com a condição, claro, de que os agentes deste processo tenham a coragem política de mudar as coisas". A coragem de que fala Foucault é exigida não somente no momento de se mostrar em ruptura com os padrões socialmente aceitos, mas, principalmente, na transformação de si mesmo nos jogos da verdade.

É preciso coragem para mudar as relações estratégicas constituídas pelas políticas de verdade que nos atravessam e agenciam as possibilidades do nosso próprio ser, uma vez que, com tais mudanças nos nossos saberes, não se trataria simplesmente de recusar uma ou outra demanda singular que nos desagrada, mas, muito mais profundamente, trata-se de recusar todo um campo de verdades pelo qual identidades nos são ofertadas, sentidos são conferidos às nossas práticas e nossos direitos são constituídos. Na historicização dos jogos de verdade não se deslegitimam simplesmente alguns espaços inconvenientes dos campos epistemológicos analisados, ao contrário, arriscando-se nesta reflexão, o autor embarga todo um sistema de verdades com pretensões universais, o qual pretenderia fundamentar normativamente nossas vidas. Uma vez que nosso presente se constitui nas políticas de verdade que sustenta, trata-se de uma recusa que, em suma, torna inviáveis importantes referências que delimitam nossa realidade atual. Assim, o ato de recusar políticas de verdade que formam o nosso presente requer não só um trabalho de reflexão sobre suas contingências, mas também a coragem de, transgredindo este presente, viver sem as suas referências. Tal "militância filosófica" contra as políticas contemporâneas de verdade, levada a cabo por Foucault encontra no seu estudo do cinismo algumas ressonâncias importantes por esclarecerem o engajamento político foucaultiano.

Foucault aponta em vários momentos que o objetivo de sua crítica é operar um "desassujeitamento" (FOUCAULT, 2015, p. 39) de nós mesmos no jogo das políticas de verdade. Nas recusas de sujeições no jogo da política da verdade, no entanto, vimos que o trabalho arqueogenealógico empreendido na 
especificidade dos campos de saber, não pretendia alcançar uma liberdade ideal ou transcendente, contrária às suas concepções de verdade e de poder. A verdade, enquanto produto histórico que possui condições de possibilidade no campo do saber, não é um destino transcendente do homem e que lhe permitiria alcançar a liberdade. O poder, enquanto multiplicidade de forças relacionais, não é considerado por Foucault nos termos da legitimidade, como se pudesse estar fundado em um direito que asseguraria a liberdade humana. Ao contrário, ao pensar a liberdade como prática local e interna às relações de poder-saber, Foucault se engaja na busca das possíveis resistências a estes jogos de verdade. Os sistemas de saber-poder que instauram os discursos verdadeiros não saturam completamente as possibilidades de resistência, pois, "[...] no centro da relação de poder, 'provocando-a' sem cessar, existe a rebeldia do querer e a intransitividade da liberdade" (FOUCAULT, 1994d, p. 238). Assim, através de uma reflexão histórica-filosófica encontra-se implicada, no coração mesmo do programa teórico-político foucaultiano, a busca dos espaços possíveis de liberdade nos quais podemos inventar outras formas de vida.

O novo quadro teórico de Foucault na década de 1980 precisa ser compreendido à luz desta desta proposta política. É no quadro do desdobramento de suas investigações sobre as possibilidades de desassujeitamento que as noções de verdade e subjetividade são investigadas nas experiências antigas de constituição de si. Nas relações que podemos estabelecer entre nós mesmos e a verdade ao refletirmos sobre a subjetividade é também preciso pensar as práticas possíveis de liberdade. Assim, Foucault as abordará no campo da ética, ao pensar a ética não como um conjunto de prescrições orientadas por um ideal transcendental, mas sim como a "forma refletida que a liberdade toma" (FOUCAULT, 1994d, p. 712). Trata-se, nestes últimos estudos, de contrapor as políticas de verdade atuais, que prenderiam nossas "formas de reflexividade" (FOUCAULT, 1994d, p. 443) (relações de si a si) a acepções substancialistas, transcendentes ou transhistóricas da subjetividade, às práticas de constituição do sujeito na Antiguidade, as quais estariam voltadas para uma ultrapassagem de si.

Tais análises das práticas de si antigas, apesar de voltadas a períodos históricos longínquos, não deixam de ser um modo de buscar a construção de alternativas ao presente. Após traçar os modos de assujeitamentos modernos pela verdade, neste momento derradeiro de suas pesquisas Foucault deseja mostrar a possibilidade de outros regimes de verdade, de outras formas da relação do sujeito com a verdade. Em oposição à estrutura cristã de coerção do sujeito à produção de um discurso verdadeiro sobre si mesmo, que funcionaria com o objetivo de fazer com que o sujeito renuncie aos seus desejos e a tudo o que possa haver de pecaminoso em sua alma, nos seus últimos estudos Foucault dará uma atenção especial ao cuidado de si (epiméleia heautoû) como "estilística da existência" (FOUCAULT, 1984, p. 89). Tal estilística da existência pode ser entendida como uma atividade em que, refletindo e agindo de modo a viver uma vida verdadeira, o sujeito transforma a si mesmo e aos outros pelo exercício da verdade. Era preciso, portanto, neste momento de seus estudos, analisar as experiências do cuidado de si em um período de nossa cultura em que as práticas de reflexividade ainda não haviam se transformado em formas de sacrifício de si, presentes no ascetismo cristão.

No que se refere ao tema do cuidado de si, o curso A coragem da verdade, de 1984, merece especial atenção por ser nele que Foucault desenvolve sua análise do cinismo. O cinismo ganha grande relevância na medida em que "[...] faz da vida, da existência, do bíos o que poderíamos chamar de uma aleturgia, uma manifestação da verdade" (FOUCAULT, 2011a, p. 150). A ideia de aleturgia aparece aqui como ritual de produção da verdade, ou seja, como prática de determinados procedimentos que permitem a manifestação da verdade. Tal ideia aparece como oposta ao desvelamento da verdade ou à demonstração de uma verdade epistemológica. Nas formas aletúrgicas, os atos feitos por alguém manifestariam uma verdade reconhecida por outros no seu próprio enlace com a subjetividade. Nas aleturgias da verdade não 
estão em jogo condições de possibilidade internas à lógica dos enunciados, não se pergunta pelas "[...] estruturas próprias dos diferentes discursos que se propõem e são recebidos como discursos verdadeiros" (FOUCAULT, 2011a, p. 4). Em outras palavras, a verdade como produção aletúrgica está vinculada muito mais a uma forma manifesta de conduta do que a regras internas de um discurso. Na aleturgia, então, se manifesta um tipo de verdade que se faz no engajamento subjetivo como potência ética, tendo na coragem requisitada por estes atos a autenticação desta verdade. Assim, ao desenvolver em seu último curso esta outra compreensão de verdade, Foucault analisará os seus efeitos no trabalho de transformação de si e dos outros.

Encerrado alguns meses antes de sua morte, este curso pode ser considerado, como afirma Gros, um "testamento filosófico" em que, "[...] retornando com Sócrates às raízes da filosofia, Foucault decide inscrever aí a totalidade da sua obra crítica" (GROS, 2011, p. 303). Neste momento, os textos de Platão mostram para Foucault a possibilidade de entender a missão socrática e o próprio objetivo da filosofia como um "[...] dizer-a-verdade corajoso que visa transformar o modo de ser do seu interlocutor, para que ele aprenda a cuidar corretamente de si mesmo" (GROS, 2011, p. 307). Tal objetivo filosófico é retomado numa vertente ousada pelos cínicos e por diferentes movimentos na história Ocidental. Trata-se aqui de uma ousadia filosófica principalmente porque para manifestar uma vida verdadeira é preciso estar disposto a se expor a muitos riscos e a um exercício constante de si. É preciso ousar para se colocar em questão, para dar razão de si mesmo, pois, cuidar de si pela verdade exige uma série de provações, de autocríticas e de enfrentamentos que levariam à construção de um modo de ser no ultrapassamento de si.

$\mathrm{Na}$ análise foucaultiana do cinismo vemos que o engajamento filosófico exigido para viver uma vida verdadeira contrasta com as formas do engajamento que se dariam em nome de uma verdade ou em nome de outro mundo, um mundo transcendente. O engajamento filosófico encontrado por Foucault principalmente no cinismo manifesta sua força não ao se referir a um conjunto fechado de saberes e verdades a ser enunciados, mas na sua atitude face à existência. Nesta questão sobre as diferentes formas de se compreender o modo de engajamento da filosofia Sócrates é tomado como uma figura emblemática por Foucault. A partir das concepções socráticas do cuidado de si poderíamos observar "[...] dois desenvolvimentos diferentes na história da filosofia ocidental” (FOUCAULT, 2011a, p. 138): de um lado, o cuidado de si que levaria ao reconhecimento da alma como ontologicamente distinta do corpo, o qual daria inicio ao discurso da metafísica; de outro, o cuidado de si como maneira de ser, como estética da vida, o qual levaria à pergunta pela forma de vida verdadeira e, na análise do cinismo, acarretaria na identificação da vida filosófica com uma vida outra.

Com Sócrates se abriria um horizonte bifurcado no qual se coloca o questionamento sobre a tarefa da filosofia: aceder pela ascese a uma verdade transcendente ou transformar-se pela prática de uma verdade imanente ao modo de vida? Neste horizonte, uma das possibilidades ligada à conduta de Sócrates seria pensar a tarefa filosófica como "[...] certa prática da verdade que seja ao mesmo tempo uma prática de si" (GROS, 2004, p. 162). A filosofia apareceria desta forma mais como incitação ao cuidado de si do que ao estudo da verdade como transcendental. Tem-se, a partir daí, o desenvolvimento de uma orientação ética que, nascida em seu interior, não se prenderia unicamente ao campo da filosofia, mas tomaria corpo em experiências de reflexividade distintas. Foucault encontra uma articulação socrática entre coragem, cuidado de si e dos outros e verdade irredutível ao pensamento metafísico. A tarefa política da filosofia toma a forma de uma incitação ética de transformação de si pelo cuidado que devemos manter com o estilo de nossa existência. Este cuidado de si socrático teria sido desenvolvido não só na Antiguidade e nos campos que se intitulam filosóficos, mas em experiências diversas de reflexividade que, na história da cultura ocidental, levam adiante a preocupação do cuidado que devemos assumir na conquista de um estilo de existência. 
Neste cuidado de si comum a Sócrates e ao cinismo se percebe uma relação imanente com a existência cotidiana na cidade. Aqui o bios é o objeto da filosofia porque ela é "[...] concebida como um empreendimento essencialmente 'prático"' (LORENZINI, 2010, p. 474). A teoria e a prática são inseparáveis nesta compreensão da filosofia como cuidado de si. Na prática filosófica é preciso tornar-se visível na sociedade para provocar os outros a também levar adiante a tarefa de cuidar de si mesmos. Constrói-se assim uma relação com a verdade manifesta na vida que seria contrária à transcendência metafísica. Como afirma Marie-Odile Goulet-Cazé (2013, p. 107), "Sócrates transmitiu ao cinismo isto que Foucault chama [...] o cuidado de si mesmo - por oposição ao estudo do cosmos que a filosofia pré-socrática teria privilegiado - assim também como a coragem do dizer verdadeiro e a ideia de que o filósofo tem uma missão a exercer entre os seus contemporâneos". Desta forma, nesta corrente socrática do cuidado de si, o cinismo que interessa a Foucault é visto mais como uma atitude que se manifesta publicamente entre seus contemporâneos do que propriamente como uma doutrina que deveria ser propagada.

Explicando como se aplica o princípio de uma vida verdadeira no cinismo, Foucault afirma quatro sentidos segundo os quais algo pode ser dito verdadeiro no pensamento grego clássico. É verdadeiro, primeiramente, aquilo que não é dissimulado, aquilo que não pode ser oculto. Em segundo lugar, é verdadeiro o que não se mistura ou que não recebe adições. Como terceiro sentido do que é verdadeiro entende-se aquilo que é reto, se expondo sem rodeios conforme uma convicção, sem se curvar para agradar os ouvidos de seus interlocutores. E, finalmente, é verdadeiro o que não se corrompe, o que permanece imutável. A verdade que se encontra na verdadeira vida (alethès bíos) preserva estes quatro sentidos: uma vida não dissimulada, não misturada, reta e incorruptível.

Estes quatro sentidos da verdade se manifestam na vida cínica através de uma extrapolação de suas características no escândalo de uma vida que se faz verdadeira. Ao levar tais fundamentos da verdade ao limite, de modo polêmico e arriscado, o cinismo coloca-se também no limite da própria filosofia. Ele está em seu interior, mantém-se fiel à busca da verdade, mas, ao mesmo tempo, tendo na vida o seu principal objeto, e promovendo através dela um exagero caricatural da verdade, torna-se insuportável e muitas vezes marginalizado pelas escolas de filosofia com maior prestígio, as quais são incapazes de se reconhecer nele. Isso se dá porque o cinismo busca seguir estes quatro sentidos da verdade tendo como princípio de vida "mais fundamental e mais característico" um famoso lema, "altera a moeda" (FOUCAULT, 2011a, p. 211) (parakharáxon to nómisma). Se Sócrates tinha a sua missão conferida pelo oráculo de Delfos, Diógenes teria igualmente a sua própria missão. A missão de Diógenes, no entanto, era conferida por este imperativo de trocar, alterar, mudar o valor da moeda. Se a alteração da moeda se faria apagando sua efígie para mostrar o seu verdadeiro valor, reduzindo o valor simbólico atribuído socialmente ao valor verdadeiro do metal de que a moeda é feita, assim também, alterar os costumes, as regras, as convenções, seria desafiar o consenso e rejeitar os princípios da vida social para mostrar de que é feita uma vida verdadeira.

O esclarecimento desta atitude cínica de manifestação da verdade pela alteração dos costumes pode ser encontrado na própria origem de sua denominação. Cínico é aquele que lembra o cão, que sustenta um estilo de vida de cão. Assim, na identificação da vida cínica com a vida de cão podem-se observar os quatro sentidos da verdade no pensamento grego. Como os cães, o cínico é aquele que manifesta uma vida sem simulações, porque não tem pudor, não se envergonha de levar uma vida pública, completamente visível nas ruas da cidade. Em segundo lugar, sua vida é pura como a vida dos cães. Sem misturas, porque, reduzida ao elementar, ela é indiferente às riquezas e aos luxos valorizados socialmente e não se prende a nada, buscando satisfazer somente as necessidades imediatas. Em terceiro lugar, à maneira dos cães, os cínicos manifestam uma vida reta, fazendo valer o seu discernimento ao latir, insultar e brigar contra seus 
inimigos. E, em quarto lugar, a vida cínica assemelha-se à vida do cão de guarda, soberana e sempre disposta a dedicar-se à proteção daqueles que têm o seu amor. Como sintetiza Foucault: "Vida de impudor, vida adiáphoros (indiferente), vida diakritikós (diacrítica, de distinção, de discriminação, vida de certo modo latida) e vida phylaktikós (vida de guarda, de cão de guarda)" (FOUCAULT, 2011a, p. 214). Vida não dissimulada porque desavergonhada e transparente a todos. Pura, sem misturas, porque se trata de uma vida indiferente e independente das comodidades que seriam desejadas por outros. Uma vida não curvada, porque, ao afastar-se da conformidade às convicções, torna-se capaz de entrar em disputas, ou seja, é capaz de insultar para não trair a si. Finalmente, vida incorruptível porque militante, porque engajada sempre em sua tarefa de manifestação da verdade.

Os contornos da atitude cínica, então, estão ligados a esta exacerbação da verdade manifesta na própria existência que denuncia a falsidade dos costumes. O cínico é aquele que faz com "[...] que as outras vidas, a vida dos outros, apareçam como não sendo nada mais que uma moeda falsa, uma moeda sem valor" (FOUCAULT, 2011a, p. 215). A vida cínica aparece, então, como vida outra em relação à vida convencional. No entanto, a manifestação de uma vida outra como vida verdadeira seria refletida, segundo Foucault, em experiências históricas variadas. Assim, algumas destas características da atitude cínica, que encontram na versão antiga uma experiência privilegiada, também poderiam ser percebidas em outros momentos da cultura ocidental.

Uma vida verdadeira porque transgressora em relação aos padrões habituais é a característica do cinismo. $\mathrm{O}$ aspecto transgressivo e corajoso presente na manifestação cínica - de uma verdade aletúrgica, não-epistemológica, de uma verdade que se faz mais pela recusa violenta da redução dos valores a suas contingências do que pela instituição de um universal, de uma verdade que exige um engajamento ético singular - é aquilo que parece mais valioso e que Foucault reconhece em suas diferentes formas de transferência na história de nossa cultura. A própria ação política e intelectual de Foucault também se efetua segundo estas diretrizes da atitude cínica: sua pesquisa não propõe uma verdade de maior valor epistemológico, pois não supõe um sujeito de conhecimento, ao contrário, questiona os saberes ao mesmo tempo em que reconhece o caráter ficcional de sua pesquisa e daqueles mesmos saberes, dos quais ele revela suas condições de possibilidade histórica; não institui outros universais, pois reconhece o caráter perspectivo e histórico de todo discurso, atuando, assim, ao desmascarar a contingência das políticas de verdade atuais; não propõe uma moral, mas, proibindo-se de recorrer às facilidades teóricas oferecidas pela tradição, exige uma rigorosa ética intelectual no ultrapassamento de si mesmo; não se volta aos temas metafísicos consagrados na história da filosofia, mas problematiza as verdades que formam nossa vida cotidiana; não separa a especulação teórica da prática, mas, pondo em questão a realidade atual, concebe sua filosofia como fundamentalmente prática; e, finalmente, não procura assegurar apenas a aquisição dos conhecimentos, mas faz da filosofia um exercício de si e a provocação dos outros na transformação do mundo.

$\mathrm{Na}$ aproximação que se pode fazer entre a crítica foucaultiana e o cinismo vemos, portanto, que aquilo que seria identificado como a própria prática da filosofia está interligado às três problemáticas centrais de suas pesquisas. A questão arqueológica do saber enquanto estudo das condições de possibilidade da verdade, a genealogia das estruturas do poder e a análise dos modos de subjetivação apoiam-se mutuamente na tarefa filosófica da alteração dos valores. Assim, no seu último curso Foucault parece nos alertar para o fato de que vinculando uma às outras suas as reflexões sobre a verdade, sobre o poder e sobre as formas de subjetivação ética poderemos criar novas formas de vida no exercício da liberdade. 


\section{NOTAS}

1. Em seu primeiro curso no Collège de France Foucault mencionará o curso de linguística geral de Saussure como um exemplo de um "operador epistemológico" que “[...] torna possível não a coerência, o rigor, a verdade ou a cientificidade do discurso, mas sua existência” (FOUCAULT, 2011c, p. 8).

2. Ver Foucault (1976, p. 115-116).

\section{REFERÊNCIAS}

ARISTÓTELES. 1984. Metafísica. São Paulo: Abril Cultural.

CANDIOTTO, C. 2010. Foucault e a crítica da verdade. Belo Horizonte: Autêntica; Curitiba: Champagnat.

COLOMBANI, M. C. 2008. Foucault y lo politico. Buenos Aires: Prometeo Libros; São Paulo: Parábola Editorial.

D’ALLONNES, O. R.2009. Michel Foucault: les mots contre les choses. In: ARTIERES, P. Les mots et les choses de Michel Foucault: regards critiques 1966-1968. Caen: Presses Universitaires de Caen, IMEC Éditeur.

DESCOMBES, V. 1979. Le même et l'autre. Paris: Les Éditions de Minuit.

DUARTE, A. 2010. Vidas em risco. Rio de Janeiro: Forense Universitária.

ERIBON, D. 1996. Michel Foucault e seus contemporâneos. Jorge Zahar.

FOUCAULT, M. 1963. Naissance de la clinique. Paris: Presses Universitaires de France.

. 1966. Les mots et les choses: une archéologie des sciences humaines. Paris: Gallimard.

. 1969. L’arquéologie du savoir. Paris: Éditions Gallimard.

. 1971. L'ordre du discours. Paris: Éditions Gallimard.

. 1976. Histoire de la sexualité I: la volonté du savoir. Paris: Gallimard.

. 1984. Histoire de la sexualité III: le souci de soi. Paris: Gallimard.

. 1994a. Dits et écrits. Paris: Éditions Gallimard. v. 1.

. 1994b. Dits et écrits. Paris: Éditions Gallimard. v. 2.

. 1994c. Dits et écrits. Paris: Éditions Gallimard. v. 3.

. 1994d. Dits et écrits. Paris: Éditions Gallimard. v. 4.

.2011a. A coragem da verdade: o governo de si e dos outros II. Curso no Collège de France (1983-

1984). São Paulo: WMF Martins Fontes. 
.2011b. Le beau danger: entretien avec Claude Bonnefoy. Paris: Éditions de l'EHESS.

.2011c. Leçons sur la volonté de savoir: cours au Collège de France 1970-1971. Paris: Seuil/Gallimard.

2015. Qu'est-ce que la critique? Suivi de La culture de soi. Paris: Vrin.

GOULET-CAZÉ, M.-O. 2013. Michel Foucault et sa vision du cynisme dans Le courage de la vérité. In: LORENZINI, D.; REVEL, A.; SFORZINI, A. (Ed.). Michel Foucault: éthique et vérité 1980-1984. Paris: Vrin.

GROS, F. 2004. A parrhesia em Foucault (1982-1984). In: GROS, F. (Ed.). Foucault, a coragem da verdade. São Paulo: Parábola.

. 2011. Situação do curso: a coragem da verdade. In: FOUCAULT, M. A coragem da verdade: o governo de si e dos outros II. Curso no Collège de France (1983-1984)". São Paulo: Editora WMF Martins Fontes.

2012. Michel Foucault. Paris: Presses Universitaires de France.

LORENZINI, D. 2010. La vie comme "réel" de la philosophie: Cavell, Foucault, Hadot et les techniques de l'ordinaire. In: LAUGIER, S. La voix et la vertu: variétés du perfectionnisme moral. Paris: PUF.

2014. La politiques des conduites, pour une histoire du rapportentre subjectivation éthique et subjectivité politique. Paris. 492 f. Tese (Doutorado) - Université Paris-Est Créteil.

NIETZSCHE, F. 2001. A gaia ciência. São Paulo: Companhia das Letras.

PALTRINIERI, L. 2012. L'expérience du concept: Michel Foucault entre épistémologie et histoire. Paris: Publications de la Sorbonne.

PLATÃO. 2004. Fédon. São Paulo: Nova Cultural.

SARTRE, J.-P. 2009. Jean-Paul Sartre répond. In: ARTIERES, P. Les mots et les choses de Michel Foucault: regards critiques 1966-1968. Caen: Presses Universitaires de Caen, IMEC Éditeur.

SAUSSURE, F. 2005. Cours de linguistique générale. Paris: Éditions Payot et Rivages. 